\title{
ATRIBUTOS FÍSICOS E QUÍMICOS DE UM LATOSSOLO VERMELHO EUTROFÉRRICO SOB DIFERENTES SISTEMAS DE PREPARO $\left({ }^{1}\right)$
}

\author{
ORLANDO MELO DE CASTRO $\left({ }^{2}\right)$; SIDNEY ROSA VIEIRA $\left({ }^{2 *}\right)$; GLÉCIO MACHADO SIQUEIRA $\left({ }^{3}\right)$; \\ CRISTIANO ALBERTO DE ANDRADE $\left(^{2}\right)$
}

\begin{abstract}
RESUMO
O objetivo deste trabalho foi avaliar o efeito de diferentes sistemas de preparo do solo sobre os atributos físicos e químicos e sua relação com o desenvolvimento de raízes da cultura do milho (Zea mays L.). O experimento foi realizado em Campinas (SP), Brasil. As amostragens foram realizadas no ano agrícola de 1990/1991 após oito anos de implantação do experimento, quando o campo estava cultivado com milho cultivar C-606. Os sistemas de preparo avaliados foram: semeadura direta, preparo com escarificador e preparo convencional, em parcelas de 7,5 $\mathrm{m}$ x 15,0 $\mathrm{m}$ com três repetições para cada um dos sistemas de preparo. Os atributos físicos e químicos avaliados foram: densidade do solo, resistência do solo à penetração, infiltração, condutividade hidráulica, matéria orgânica (MO), fósforo (P), potássio $(\mathrm{K})$, cálcio $(\mathrm{Ca})$, magnésio $(\mathrm{Mg}), \mathrm{pH}$ e saturação por bases $(\mathrm{V} \%)$. A densidade de raízes de milho foi determinada por meio do método de tradagem. O solo sob semeadura direta proporcionou melhores condições gerais de fertilidade de 0,0-0,1 m de profundidade, comparativamente aos tratamentos com preparo mecânico, e abaixo dessa profundidade o efeito foi inverso. Entretanto, tais diferenças não influenciaram o desenvolvimento radicular das plantas de milho. Os atributos físicos medidos permitiram identificar camadas mais adensadas provocadas pela profundidade e repetição das operações mecânicas para preparo do solo e estas reduziram a densidade de raízes do milho.
\end{abstract}

Palavras-chave: semeadura direta; preparo com escarificador; preparo convencional; sistemas de manejo; Zea mays L..

\section{ABSTRACT \\ PHYSICAL AND CHEMICAL ATTRIBUTES OF A RHODIC HAPLUDOX UNDER DIFFERENT TILLAGE SYSTEMS}

The objective of this work was to evaluate the effect of different soil tillage systems on soil physical and chemical attributes and their relationships with root development of maize (Zea mays L.) crop. The experiment was conducted at the Campinas Experimental Center of Instituto Agronômico, located in Campinas, SP, Brazil. The measurements were made during the 1990/91 summer cropping season when the field was cultivated with the cultivar C-606 of mayze crop. The tillage systems evaluated were: no tillage, soil tilled with chisel plow, and conventional soil tillage with disk plow and harrow, in plots measuring $7.5 \mathrm{~m}$ by $15.0 \mathrm{~m}$, with three replications each. The soil physical and chemical attributes evaluated were: bulk density, soil penetration resistence, infiltration rate, hydraulic conductivity, organic matter, phosphorus, potassium, calcium, magnesium, $\mathrm{pH}$ and base saturation. The maize crop root density was determined using the auger method. The soil under no tillage showed the best soil fertility of the layer 0,0-0,1 $\mathrm{m}$ as compared to the soil tilled treatments. At the layers bellow that depth, the effect was the reverse. However, these differences did not affect the maize crop root development. The measured soil physical attributes allowed the identification of higher density layers caused by depth and repetition of mechanical operations of soil tillage, which contributed to reduce the maize root density.

Key words: no tillage, chisel plow, conventional tillage, soil management systems, Zea mays L..

$\left({ }^{1}\right)$ Recebido para publicação em 30 de janeiro de 2007 e aceito em 30 de abril de 2009.

$\left({ }^{2}\right)$ Instituto Agronômico (IAC), Campinas, SP. Caixa Postal 28, 13020-902 Campinas (SP). E-mail: omcastro@iac.sp.gov.br, sidney@iac.sp.gov.br ${ }^{*}$ ) Autor correspondente; andrade@iac.sp.gov.br.

$\left({ }^{3}\right)$ Doutorando em Engenharia para o Desenvolvimento Rural, Universidade de Santiago de Compostela (USC), Campus Universitario, 27071, Lugo, Espanha. Bolsista MAEC-AECID. E-mail: glecio.machado@rai.usc.es. 


\section{INTRODUÇÃO}

De modo geral, no sistema de semeadura direta, comparativamente ao preparo convencional, verifica-se maior disponibilidade de nutrientes (KLuthCouski et al., 2000; RHEINHeImer e ANGHinONI, 2001; Conte et al., 2003; Falleiro et al., 2003) e acúmulo de matéria orgânica nas camadas superficiais do solo, além de aumento da acidez em profundidade no perfil do solo, uma vez que o calcário é aplicado superficialmente, sem posterior incorporação (CıOTTA et al., 2004).

As boas condições químicas para o crescimento radicular na camada $0,0-0,1 \mathrm{~m}$, a baixa mobilidade do Ca para as camadas mais profundas do solo (Almeida et al., 2005) e níveis mais altos de acidez em profundidade (СіоттA et al., 2004) podem promover a concentração de raízes em camadas superficiais, em áreas sob o sistema de semeadura direta. O aprofundamento do sistema radicular é desejável porque confere às plantas maior resistência a períodos de baixa precipitação pluvial, possibilita maior absorção de nutrientes e aumento da eficiência das fertilizações, pela exploração de maior volume de solo. No entanto, há de se considerar também os atributos físicos do solo relacionados ao desenvolvimento radicular e à dinâmica da água no solo, como agregação, densidade do solo, macro e microporosidade e resistência do solo à penetração.

O não-revolvimento do solo no sistema de semeadura direta pode aumentar a densidade na camada superficial quando comparado ao preparo convencional, em função da diminuição da porosidade superficial (BERTOL et al., 2001). A redução do volume de macroporos, concomitantemente ao aumento do volume de microporos, implica maior força de retenção da água no solo e, portanto, menor disponibilidade dessa água. Por outra parte, o sistema de semeadura direta mantém na superfície do solo os resíduos culturais, que favorecem melhoria da estrutura do solo (VolK et al., 2004), aumentando a disponibilidade de água para as culturas (STONE e MOREIRA, 2000).
Com o preparo mecânico do solo, normalmente, tem-se valores de densidade do solo e resistência à penetração inferiores para a camada arável $(0,0-0,2 \mathrm{~m})$, mas tais valores aumentam em profundidade e podem ser iguais ou superiores aos das áreas sob semeadura direta (MARCOLAN e ANGHINONI, 2006). Também com o preparo mecânico do solo há possibilidade de formação de uma camada compactada na profundidade limite de trabalho dos implementos, o que se denomina popularmente como "pé-de-grade" ou "pé-de-arado". Essa camada compactada dificulta a infiltração de água no solo, reduz a quantidade de água armazenada e prejudica o desenvolvimento radicular (BERTOL et al., 2001).

Nota-se, portanto, que o assunto é controverso quanto ao desenvolvimento do sistema radicular das plantas nesses diferentes sistemas de preparo do solo e a relação deste desenvolvimento com atributos físicos e químicos do solo.

Nesse contexto, este trabalho teve como objetivo avaliar o comportamento de atributos físicos e químicos de um Latossolo Vermelho eutroférrico argiloso sob diferentes condições de preparo do solo.

\section{MATERIAL E MÉTODOS}

O experimento foi desenvolvido em Campinas (SP), Brasil, na latitude de $22^{\circ} 54^{\prime} 20^{\prime \prime}$ Sul, longitude de $47^{\circ} 05^{\prime} 34^{\prime \prime}$ Oeste, com altitude média de $674 \mathrm{~m}$. De acordo com a classificação de Köeppen o clima da região é do tipo Cwa. O solo da área, segundo a classificação EMBRAPA (1999), é Latossolo Vermelho eutroférrico argiloso. A composição granulométrica do solo para a área de estudo é apresentada na tabela 1. A área vem sendo cultivada com milho (Zea mays L.) ou soja [Glycine max (L.) Merrill] no verão, em rotação com aveia-preta (Avena strigosa Schieb.) no inverno, desde o ano de 1983/1984, sob três sistemas de preparo do solo: semeadura direta (SD), arado escarificador (PE) e arado de discos (PC).

Tabela 1. Composição granulométrica do solo estudado

\begin{tabular}{lcccc}
\hline Profundidade & $\begin{array}{c}\text { Areia grossa } \\
2,00-0,25 \mathrm{~mm}\end{array}$ & $\begin{array}{c}\text { Areia fina } \\
0,25-0,05 \mathrm{~mm}\end{array}$ & $\begin{array}{c}\text { Silte } \\
0,05-0,002 \mathrm{~mm}\end{array}$ & $\begin{array}{c}\text { Argila } \\
<0,002 \mathrm{~mm}\end{array}$ \\
\hline & \multicolumn{2}{c}{$\mathrm{m} \mathrm{g} \mathrm{kg}^{-1}$} & & 740,00 \\
$0,0-0,1$ & 90,00 & 90,00 & 80,00 & 743,00 \\
$0,1-0,2$ & 90,00 & 87,00 & 80,00 & 757,00 \\
$0,2-0,3$ & 93,00 & 77,00 & 73,00 & 777,00 \\
$0,3-0,4$ & 80,00 & 77,00 & 67,00 & 787,00 \\
$0,4-0,5$ & 70,00 & 73,00 & 70,00 & 770,00 \\
$0,5-0,6$ & 73,00 & 77,00 & 80,00 & \\
\hline
\end{tabular}


As amostragens físicas e químicas foram realizadas no ano agrícola de 1990/1991 em parcelas de $7,5 \mathrm{~m} \times 15,0 \mathrm{~m}$ com três repetições para cada um dos sistemas de preparo (semeadura direta, preparo escarificado e preparo convencional), após o cultivo de milho (C-606 Cargill), ou seja, após sete anos da adoção dos sistemas de preparo. O milho foi semeado com 1 $m$ de distância nas entrelinhas e deixando-se após desbaste seis plantas por metro na linha. $\mathrm{Na}$ adubação de plantio foram aplicados $10 \mathrm{~kg} \mathrm{ha}^{-1}$ de $\mathrm{N}, 50 \mathrm{~kg} \mathrm{ha}^{-1}$ de $\mathrm{P}_{2} \mathrm{O}_{5}$ e $50 \mathrm{~kg} \mathrm{ha}^{-1}$ de $\mathrm{K}_{2} \mathrm{O}$. Após 50 dias da emergência foi realizada a adubação de cobertura com $90 \mathrm{~kg} \mathrm{ha}^{-1}$ de $\mathrm{N}$ na forma de sulfato de amônio. Cinco anos antes do presente estudo havia sido realizada a aplicação de $2,4 \mathrm{t}$ ha $^{-1}$ de calcário dolomítico com incorporação mecânica nos tratamentos PE e PC, e deixando-se o corretivo na superfície do solo no SD.

O preparo com arado de discos, aqui denominado preparo convencional (PC), foi realizado com arado reversível de três discos de 28 polegadas a uma profundidade de $0,2 \mathrm{~m}$, seguido de duas passadas de grade niveladora.

O preparo com escarificador (PE) consistiu no uso de arado escarificador de sete hastes tipo oblíqua, com espaçamento entre sulcos de $0,33 \mathrm{~m}$ e profundidade de trabalho de $0,3 \mathrm{~m}$. Após a escarificação, fez-se a gradeação por duas vezes.

O sistema de semeadura direta (SD) consistiu em semeadura do milho sem preparo prévio do solo, usando semeadeira de disco ondulado para corte da palha, disco duplo na linha da semente e facão sulcador para colocação do adubo a $0,1 \mathrm{~m}$ de profundidade.

Após a colheita do milho foram abertas trincheiras de 1,5 $\mathrm{m}$ de profundidade e $1,0 \mathrm{~m}^{2}$ de área em cada parcela, para leitura da resistência à penetração com penetrômetro de bolso modelo ELE, nos primeiros $0,6 \mathrm{~m}$ de profundidade, com espaçamento entre medições de $0,05 \mathrm{~m}$. Amostras de solo solto foram coletadas nas profundidades de 0,1 , 0,3 e $0,6 \mathrm{~m}$ para determinação da umidade $\left(\mathrm{m}^{3} \mathrm{~m}^{-3}\right)$ no momento da avaliação da resistência do solo à penetração estando o solo próximo à capacidade de campo.

A densidade do solo foi determinada de acordo com CAMARGO et al. (1986), usando anéis volumétricos de $100 \mathrm{~cm}^{3}$, nas profundidades de 0,0 $0,05,0,05-0,1,0,1-0,15,0,15-0,2,0,2-0,25,0,25-0,3$, $0,3-0,45,0,45-0,6,0,6-0,75,0,75-0,9$ e $0,9-1,2 \mathrm{~m}$.
Para avaliação da densidade de raízes, utilizou-se o método da tradagem de solo ao lado de cada planta na entrelinha (ВоHм, 1979), considerando três plantas por tratamento a cada $0,1 \mathrm{~m}$ de profundidade, utilizando um trado com diâmetro de $0,07 \mathrm{~m}$ (volume de $384,85 \mathrm{~cm}^{3}$ ) até $0,6 \mathrm{~m}$ de profundidade. Cada amostra foi colocada em saco plástico e levada ao laboratório para lavagem e pesagem das raízes, expressando-se os resultados em $\mathrm{kg} \mathrm{m}^{-3}$.

O permeâmetro IAC foi utilizado para se determinar a taxa de infiltração na superfície, a 0,2 $\mathrm{m}$ e a $0,4 \mathrm{~m}$ de profundidade em dois pontos de cada parcela. Para verificar a infiltração na superfície do solo, utilizou-se um anel com $16 \mathrm{~cm}$ de diâmetro e 30 $\mathrm{cm}$ de altura, cravado no solo até $15 \mathrm{~cm}$ de profundidade. Posteriormente, foi possível determinar a condutividade hidráulica do solo saturado no campo (Kfs) (REYNOLDS e ELRICK, 1985) com duas cargas hidráulicas $(0,03 \mathrm{~m}$ e $0,06 \mathrm{~m})$, de acordo com a equação 1:

$$
Q=\left(\frac{2 \pi H^{2}}{C}+\pi a^{2}\right) K f s\left(\frac{2 \pi H}{C}\right) \varnothing_{m}
$$

sendo: $K f S$ é a condutividade hidráulica do solo saturado no campo; $\varnothing_{m}$ potencial matricial de fluxo; $Q$ fluxo constante; $H$ carga hidráulica; $C$ fator de geometria; e $a$ raio do orifício onde as medições foram feitas. A solução da equação (1) gera valores de Kfs em $\mathrm{cm} \mathrm{h}^{-1}$. A infiltração é calculada a partir do volume de água que penetra no solo, em litros, dividido pela área de molhamento do orifício, em $\mathrm{m}^{2}$, na carga hidráulica maior.

Amostras para análise química do solo foram coletadas entre as linhas de plantio com o auxílio de trado holandês em 15 pontos por parcela, para a composição de uma amostra composta para as seguintes profundidades: $0,0-0,1,0,1-0,2,0,2-0,3,0,3-$ $0,4,0,4-0,5$ e $0,5-0,6 \mathrm{~m}$. Os atributos químicos analisados foram: matéria orgânica $(\mathrm{MO})$, fósforo $(\mathrm{P})$, potássio $(\mathrm{K})$, cálcio $(\mathrm{Ca})$, magnésio $(\mathrm{Mg}), \mathrm{pH}$ em $\mathrm{CaCl}_{2}$ e saturação por bases $(\mathrm{V} \%)$, determinados de acordo com metodologia descrita por RAIJ e QuAGGIO (1983).

Os resultados foram analisados estatisticamente por meio da aplicação de análise de variância (ANOVA), considerando o delineamento experimental inteiramente ao acaso e como fator de variação os sistemas de preparo do solo (semeadura direta, plantio escarificado e plantio convencional). No caso de efeito significativo dos sistemas de preparo a $5 \%$ de probabilidade $(\alpha=5 \%$ ), foi aplicado teste de Duncan ( $\alpha=5 \%$ ) para verificação de diferenças entre as médias. Todas as análises estatísticas foram realizadas utilizando o software SANEST (ZONTA e Machado, 1991). 


\section{RESULTADOS E DISCUSSÃO}

Os valores de densidade do solo $\left(\mathrm{Mg} \mathrm{m}^{-3}\right)$ apresentados na tabela 2 revelam poucas diferenças entre os tratamentos. No preparo convencional (PC) e sistema de semeadura direta (SD) houve diferenças significativas nas camadas de $0,15-0,2 \mathrm{~m}$ e $0,45-0,6 \mathrm{~m}$ de profundidade respectivamente. A diferenciação estatística da densidade do solo para o sistema de semeadura direta na camada de $0,45-0,6 \mathrm{~m}$ de profundidade não coincide com os valores de resistência à penetração, uma vez que os maiores valores de resistência neste sistema estão presentes na camada de 0,0-0,15 $\mathrm{m}$ de profundidade.

As determinações de resistência à penetração (Tabela 3), realizadas na mesma época e local da coleta dos anéis volumétricos para determinação da densidade do solo, revelam a mesma tendência dos dados de densidade do solo, porém com grau de diferenciação maior, conforme pode ser visto na tabela 3. A menor dureza do solo no preparo com escarificador (PE) é conseqüência da atuação do manejo com haste escarificadora, anualmente, até 0,30 $\mathrm{m}$ de profundidade. É importante notar que ocorre aumento mais acentuado da resistência do solo à penetração no preparo convencional (PC), crescendo 3,5 vezes da profundidade de $0,05 \mathrm{~m}$ para $0,2 \mathrm{~m}$ (maior valor), enquanto nos demais tratamentos o incremento é de apenas 1,7 vezes.

Os maiores valores de densidade do solo (Tabela 2) e resistência à penetração (Tabela 3) observados na faixa de $0,20-0,25 \mathrm{~m}$ de profundidade afetaram significativamente o crescimento radicular do milho no preparo convencional (PC) (Tabela 4). Nas camadas de 0,2-0,3 e 0,3-0,4 m, a densidade de raízes no preparo convencional (PC) é praticamente a metade da observada nos outros tratamentos, mostrando que a compactação existente nesta faixa afetou diretamente o crescimento das raízes de milho.

Rosolem et al. (1999) verificaram que valores de resistência do solo à penetração maiores que 1,30 $\mathrm{MPa}$, determinada com penetrômetro de bolso, em Latossolo Vermelho reduziram o desenvolvimento das raízes do milho cultivado em casa de vegetação. Neste trabalho, os valores de resistência à penetração são inferiores ao valor de 1,30 MPa descrito como limitante por Rosolem et al. (1999) medido com o solo na capacidade de campo, aproximadamente $0,250 \mathrm{~m}^{3} \mathrm{~m}^{-}$ 3 . O maior valor de resistência do solo à penetração neste estudo foi de 0,429 MPa na camada de 0,15-0,20 $\mathrm{m}$ de profundidade para o preparo convencional com o solo próximo à capacidade de campo, com uma umidade volumétrica de $0,245 \mathrm{~m}^{3} \mathrm{~m}^{-3}$ na camada de $0,05-0,10 \mathrm{~m}$ de profundidade e de $0,251 \mathrm{~m}^{3} \mathrm{~m}^{-3}$ na camada de 0,25-0,30 $\mathrm{m}$ de profundidade.

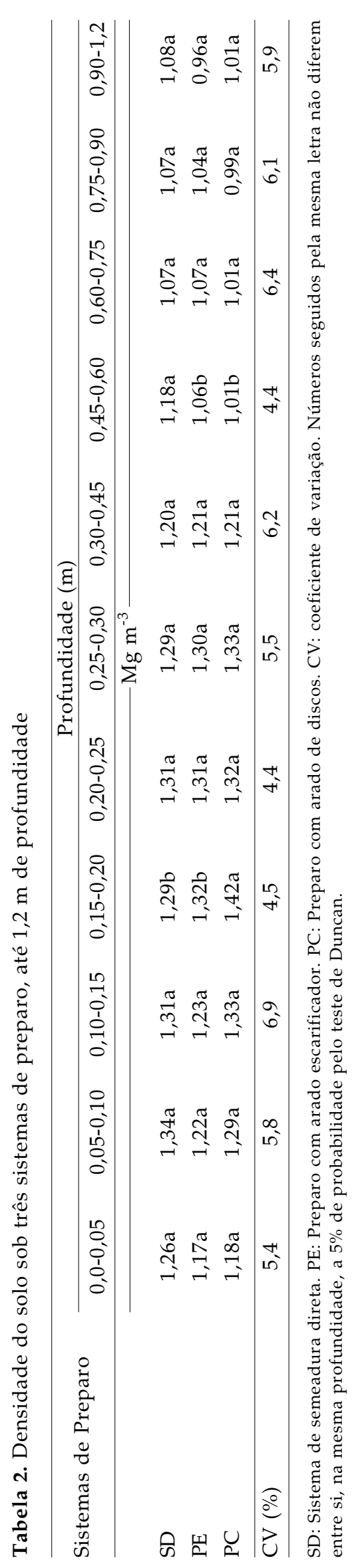


Por esta razão, vale destacar que as medições de resistência à penetração (Tabela 3 ) foram realizadas com o solo próximo à capacidade de campo.

A medida da resistência do solo à penetração na capacidade de campo é importante, uma vez que nesta umidade as raízes encontram condições ótimas para seu desenvolvimento (TAYLOR e BuRnetT, 1964); com umidades mais baixas, há maiores valores de resistência do solo à penetração (GENRO Júnior et al., 2004). Embora no sistema de semeadura direta (SD) verifiquem-se valores mais elevados de resistência à penetração até $0,2 \mathrm{~m}$ de profundidade, o desenvolvimento radicular não foi afetado, pois, conforme relatado por MARCOLAN et al. (2007), os solos não mobilizados mantêm a continuidade dos poros, o que facilita o crescimento das raízes por estes espaços. Pode-se dizer também que, para os cultivos atuais de milho com um espaçamento das entrelinhas em torno de $0,7 \mathrm{~m}$ e $0,5 \mathrm{~m}$, o sistema de semeadura direta é vantajoso, pois assegura condições estruturais adequadas para o pleno crescimento das plantas; de acordo com Volk et al. (2004) e Stone e Moreira (2000), neste sistema o não-revolvimento do solo favorece maior disponibilidade de água para os cultivos.

Os valores de infiltração e condutividade hidráulica do solo saturado, medidos na superfície, a $0,2 \mathrm{~m}$ e a $0,4 \mathrm{~m}$ de profundidade, são apresentados na tabela 5. Por serem os pontos de amostragem muito pequenos em relação à superfície considerada e devido à variabilidade espacial dos fatores do solo que regem a infiltração de água, o coeficiente de variação dos dados é médio, de acordo com a classificação de WARRICK e Nielsen (1980), especialmente das medições superficiais (cerca de 33,14\%). Em que pese esta variabilidade, os dados obtidos revelam que em SD ocorreram os maiores valores de infiltração, ou seja, até $0,2 \mathrm{~m}$ de profundidade. A $0,4 \mathrm{~m}$ de profundidade não houve diferença significativa entre tratamentos, pois nesta camada já não há influência dos implementos de preparo.

A condutividade hidráulica do solo saturado (Kfs), que rege a infiltração básica do solo, proporcionou a mesma tendência de diferenciação entre sistemas. Valores mais altos de infiltração e condutividade hidráulica nos sistemas com menor mobilização do solo, especialmente no sistema de semeadura direta, podem ser explicados devido ao maior conteúdo de matéria orgânica, pela continuidade dos poros e pela maior atividade da micro e mesofauna (FERRI et al., 2002). 
Tabela 4. Densidade de raiz de milho, em diferentes profundidades, nos três sistemas de preparo do solo

\begin{tabular}{|c|c|c|c|c|c|c|}
\hline \multirow{2}{*}{ Sistemas de Preparo } & \multicolumn{6}{|c|}{ Profundidade (m) } \\
\hline & $0,0-0,1$ & $0,1-0,2$ & $0,2-0,3$ & $0,3-0,4$ & $0,4-0,5$ & $0,5-0,6$ \\
\hline & & 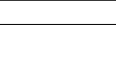 & 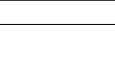 & & & \\
\hline SD & $2,56 a$ & $1,30 \mathrm{a}$ & $0,38 \mathrm{a}$ & $0,31 \mathrm{a}$ & $0,24 a$ & $0,13 a$ \\
\hline PE & $2,37 a$ & $1,25 \mathrm{a}$ & $0,40 \mathrm{a}$ & $0,27 \mathrm{a}$ & $0,15 b$ & $0,12 \mathrm{a}$ \\
\hline PC & $1,51 \mathrm{a}$ & $1,46 a$ & $0,20 \mathrm{~b}$ & $0,10 \mathrm{~b}$ & $0,15 b$ & $0,13 a$ \\
\hline CV $(\%)$ & 46,47 & 32,43 & 23,38 & 21,37 & 4,81 & 17,92 \\
\hline
\end{tabular}

SD: Sistema de semeadura direta. PE: Preparo com arado escarificador. PC: Preparo com arado de discos. CV: coeficiente de variação. Números seguidos pela mesma letra não diferem entre si, na mesma profundidade, a $5 \%$ de probabilidade pelo teste de Duncan.

Tabela 5. Valores de infiltração e condutividade hidráulica do solo saturado (Kfs) na superfície, a 0,2 $\mathrm{m}$ e a $0,4 \mathrm{~m}$ de profundidade, nos três sistemas de preparo do solo

\begin{tabular}{|c|c|c|c|c|c|}
\hline \multirow{2}{*}{ Sistemas de Preparo } & \multicolumn{3}{|c|}{ Infiltração } & \multicolumn{2}{|c|}{ Condutividade hidráulica } \\
\hline & Superfície & $0,2 \mathrm{~m}$ & $0,4 \mathrm{~m}$ & $0,2 \mathrm{~m}$ & $0,4 \mathrm{~m}$ \\
\hline & & & +2 & 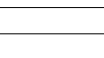 & 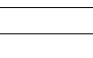 \\
\hline SD & $111,37 a$ & $112,15 a$ & $86,26 a$ & $2,33 a$ & $1,25 a$ \\
\hline PE & $62,88 \mathrm{a}$ & $54,56 b$ & $73,32 \mathrm{a}$ & $1,08 b$ & $1,04 \mathrm{a}$ \\
\hline PC & $11,88 b$ & $46,15 b$ & $73,09 a$ & $0,92 b$ & $1,04 \mathrm{a}$ \\
\hline $\mathrm{CV}(\%)$ & 33,14 & 13,74 & 22,89 & 14,75 & 23,60 \\
\hline
\end{tabular}

SD: Sistema de semeadura direta. PE: Preparo com arado escarificador. PC: Preparo com arado de discos. CV: coeficiente de variação. Números seguidos pela mesma letra não diferem entre si, na mesma profundidade, a $5 \%$ de probabilidade pelo teste de Duncan.

Apesar dos dados de densidade do solo terem evidenciado pouca diferenciação entre SD e PC próximo à superfície, deve-se lembrar que no $\mathrm{PC}$, devido à mobilização do solo, predomina a descontinuidade dos poros, enquanto no SD, embora a porosidade total possa até ser menor, ocorre um contínuo de poros que facilita a movimentação tridimensional da água (Souza e Alves, 2003). As características do solo que modificam o valor da condutividade são porosidade total, distribuição de tamanho dos poros e tortuosidade dos interstícios (Assis e LANÇAS, 2005), o que pode explicar porque o valor de infiltração na superfície do solo no sistema de semeadura direta é cerca de 10 vezes maior em relação ao PC.

Observa-se na tabela 5 que, enquanto no SD e PE ocorre pouca variação de infiltração entre camadas, no PC houve aumento mais acentuado, especialmente da superfície para a camada de $0,2 \mathrm{~m}$, consequência possivelmente da descontinuidade estrutural ao longo do perfil neste sistema, já caracterizado pelos dados de densidade do solo e da resistência à penetração.

Nas tabelas 6, 7, 8, 9, 10, 11 e 12 são apresentados os dados de análise química e a comparação estatística entre sistemas de preparo, dentro de cada profundidade estudada, para matéria orgânica $(\mathrm{MO})$, fósforo $(\mathrm{P})$, potássio $(\mathrm{K})$, cálcio $(\mathrm{Ca})$, magnésio $(\mathrm{Mg})$, pH em $\mathrm{CaCl}_{2}$ e saturação por bases $(\mathrm{V} \%)$, respectivamente.

Na tabela 6 a análise estatística mostra diferença significativa entre o teor de matéria orgânica (MO) no sistema de semeadura direta e no preparo convencional na camada mais superficial do solo. Carvalho et al. (1999) e Freitas et al. (2000) observaram valores similares de MO na camada superficial em solos argilosos manejados com semeadura direta. O acúmulo de $\mathrm{MO}$ na camada superficial do solo no sistema de semeadura direta tem sido associado ao maior aporte de fitomassa, função da adoção de sistemas mais intensivos de produção (rotação de culturas) e a diversos fatores responsáveis pela redução da taxa de mineralização da MO (CostA et al., 2003; SANTOS e Tomm, 2003). Como no presente estudo, a rotação de culturas foi a mesma nos três tratamentos, o maior teor de MO no sistema de semeadura direta deve ter ocorrido pela redução da taxa de mineralização.

O teor de fósforo $(\mathrm{P})$ extraído com resina foi significativamente maior na camada superficial no sistema de semeadura direta (Tabela 7), confirmando resultados observados por outros 
autores (Rheinheimer et al., 2003). A baixa mobilidade do $\mathrm{P}$ no perfil do solo e o efeito do preparo mecânico que promove maior contato entre o adubo e as partículas de solo, este último favorecendo a fixação do elemento nos óxidos de ferro e alumínio, ajudam a entender as diferenças verificadas entre SD e aqueles sistemas com preparo mecânico (RHEINHEIMER et al., 2003).

Tabela 6. Valores médios de matéria orgânica, em diferentes profundidades, nos três sistemas de preparo do solo

\begin{tabular}{|c|c|c|c|c|c|c|}
\hline \multirow{2}{*}{ Sistemas de Preparo } & \multicolumn{6}{|c|}{ Profundidade $(\mathrm{m})$} \\
\hline & $0,0-0,1$ & $0,1-0,2$ & $0,2-0,3$ & $0,3-0,4$ & $0,4-0,5$ & $0,5-0,6$ \\
\hline & \multicolumn{6}{|c|}{$\mathrm{g} \mathrm{dm}^{-3}$} \\
\hline SD & $31 \mathrm{a}$ & $25 a$ & $20 a$ & $22 \mathrm{a}$ & $18 \mathrm{a}$ & $17 \mathrm{a}$ \\
\hline PE & $29 a b$ & $24 a$ & $20 a$ & $18 \mathrm{a}$ & $18 \mathrm{a}$ & $17 a$ \\
\hline PC & $25 b$ & $21 \mathrm{a}$ & $18 \mathrm{a}$ & $18 \mathrm{a}$ & $18 \mathrm{a}$ & $17 \mathrm{a}$ \\
\hline CV (\%) & 6,7 & 10,2 & 17,5 & 17,5 & 7,4 & 7,0 \\
\hline
\end{tabular}

SD: Sistema de semeadura direta. PE: Preparo com arado escarificador. PC: Preparo com arado de discos. CV: coeficiente de variação. Números seguidos pela mesma letra não diferem entre si, na mesma profundidade, a $5 \%$ de probabilidade pelo teste de Duncan.

Tabela 7. Valores médios de fósforo (P resina), em diferentes profundidades, nos três sistemas de preparo do solo

\begin{tabular}{|c|c|c|c|c|c|c|}
\hline \multirow{2}{*}{ Sistemas de Preparo } & \multicolumn{6}{|c|}{ Profundidade (m) } \\
\hline & $0,0-0,1$ & $0,1-0,2$ & $0,2-0,3$ & $0,3-0,4$ & $0,4-0,5$ & $0,5-0,6$ \\
\hline & & 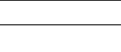 & 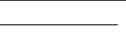 & & & \\
\hline SD & $40 a$ & $24 a$ & $4,7 \mathrm{a}$ & $3,0 \mathrm{a}$ & $2,3 a$ & $2,3 a$ \\
\hline PE & $28 b$ & $26 a$ & $6,0 a$ & $2,3 a$ & $2,7 a$ & $2,7 \mathrm{a}$ \\
\hline PC & $23 b$ & $22 \mathrm{a}$ & $4,3 a$ & $3,0 \mathrm{a}$ & $2,3 a$ & $2,7 \mathrm{a}$ \\
\hline CV (\%) & 10,5 & 26,5 & 30,5 & 37,9 & 27,3 & 38,0 \\
\hline
\end{tabular}

SD: Sistema de semeadura direta. PE: Preparo com arado escarificador. PC: Preparo com arado de discos. CV: coeficiente de variação. Números seguidos pela mesma letra não diferem entre si, na mesma profundidade, a $5 \%$ de probabilidade pelo teste de Duncan.

O P no solo em semeadura direta acumula-se predominantemente no compartimento inorgânico, principalmente em solos argilosos e com alta capacidade de adsorção desse elemento (RHEINHEIMER et al., 2003), tal qual o utilizado no presente estudo. A explicação para essa dinâmica do P no sistema de semeadura direta (SD) está relacionada com a ciclagem do elemento no sistema, uma vez que os compostos orgânicos ricos em P são preferencialmente mineralizados pela microbiota edáfica, liberando o $P$ na forma de fosfatos, que acumulam no compartimento inorgânico, tendendo, com o tempo de adoção do sistema, a incrementar as formas mais lábeis de $\mathrm{P}$ no solo da camada superficial, como o $\mathrm{P}$ extraído com resina e o P extraído com $\mathrm{NaHCO}_{3}$ (Rheinheimer e ANGHinOnI, 2001; ToKURA et al., 2002).

Além da localização e fixação do fertilizante fosfatado no sistema de semeadura direta e do padrão de ciclagem, as substâncias orgânicas de baixa massa molecular liberadas na decomposição gradual da palhada na superfície do solo auxiliam na diminuição dos sítios de adsorção e da energia de ligação fosfatosolo, contribuindo para a maior disponibilidade do P (RHEINHEIMER e ANGHINONI, 2001).

O teor de potássio (K, Tabela 8) foi maior no solo preparado com escarificador, nas camadas $0,1-0,2 \mathrm{~m}$ e $0,2-0,3 \mathrm{~m}$. Não existe uma razão clara para este acúmulo, superior até ao sistema de semeadura direta na camada 0,1-0,2 m. SANTOS e Томм (2003), estudando o comportamento de atributos químicos do solo sob diferentes tipos de preparo do solo em um Latossolo Vermelho distrófico, também observaram maiores teores de potássio para o preparo com escarificador para a camada superficial do solo até $0,15 \mathrm{~m}$ de profundidade. Assim, pode-se dizer que o acúmulo de potássio em solos de baixa CTC é muito dependente do regime de chuvas e drenagem do solo, podendo ser facilmente levado pela água de drenagem se as condições forem favoráveis para isto. 
Tabela 8. Valores médios de potássio (K), em diferentes profundidades, nos três sistemas de preparo do solo

\begin{tabular}{|c|c|c|c|c|c|c|}
\hline \multirow{2}{*}{ Sistemas de Preparo } & \multicolumn{6}{|c|}{ Profundidade (m) } \\
\hline & $0,0-0,1$ & $0,1-0,2$ & $0,2-0,3$ & $0,3-0,4$ & $0,4-0,5$ & $0,5-0,6$ \\
\hline & \multicolumn{6}{|c|}{ mmolc dm ${ }^{-3}$} \\
\hline SD & $2,5 \mathrm{a}$ & $1,0 \mathrm{~b}$ & $0,6 \mathrm{ab}$ & $0,6 \mathrm{a}$ & $0,6 \mathrm{a}$ & $0,6 \mathrm{a}$ \\
\hline PE & $3,3 a$ & $2,2 a$ & $0,8 \mathrm{a}$ & $0,7 \mathrm{a}$ & $0,6 \mathrm{a}$ & $0,6 a$ \\
\hline PC & $2,3 a$ & $1,4 \mathrm{~b}$ & $0,4 b$ & $0,7 \mathrm{a}$ & $0,2 \mathrm{a}$ & $0,2 \mathrm{~b}$ \\
\hline $\mathrm{CV}(\%)$ & 23,3 & 20,9 & 18,2 & 36,5 & 36,5 & 30,6 \\
\hline
\end{tabular}

SD: Sistema de semeadura direta. PE: Preparo com arado escarificador. PC: Preparo com arado de discos. CV: coeficiente de variação Números seguidos pela mesma letra não diferem entre si, na mesma profundidade, a $5 \%$ de probabilidade pelo teste de Duncan.

Santos e Tomm (2003) descrevem que nos sistemas conservacionistas, os fertilizantes à base de K são depositados na superfície ou na linha de semeadura e, além disso, os resíduos vegetais são deixados na superfície, o que faz com que esse elemento se acumule nas camadas mais superficiais do solo.

Nos teores de cálcio (Ca, Tabela 9) e magnésio ( $\mathrm{Mg}$, Tabela 10) no solo abaixo de $0,1 \mathrm{~m}$ de profundidade, notam-se valores significativamente maiores para o preparo com escarificador (PE) e convencional (PC). Uma calagem com 2,4 t calcário dolomítico $\mathrm{ha}^{-1}$, realizada em toda a área experimental, cinco anos antes da presente amostragem, pode explicar estes resultados, considerando que o corretivo foi incorporado de acordo com os preparos de solo (PE e PC) e que no sistema de semeadura direta (SD) não houve incorporação. Assim, o calcário localizado na superfície do solo reduz a reação do corretivo, pelo menor contato com as partículas de solo, retardando também sua ação em profundidade no perfil (СіотTA et al., 2004). Nas camadas inferiores a $0,1 \mathrm{~m}$ de profundidade, no sistema de semeadura direta, não se verificou a mesma eficiência de correção da acidez do solo que no preparo escarificado (PE) e convencional (PC), uma vez que o Ca e Mg é mais lentamente disponibilizado no sistema de semeadura direta (SD), comparativamente ao sistema convencional. Entretanto, ao considerar que a acidificação é mais intensa a partir da superfície do solo, a localização do calcário no sistema de semeadura direta pode minimizar a acidificação onde esta é mais intensa (СІоттA et al., 2004), o que se pode verificar pelos resultados de $\mathrm{pH}$ na tabela 11 , em que não se verificou diferenças de $\mathrm{pH}$ entre os sistemas de preparo até $0,2 \mathrm{~m}$ de profundidade. Em profundidade no perfil do solo, o uso do arado de discos promoveu maior eficiência de correção da acidez, seguido pelo preparo com escarificador e depois pelo sistema de semeadura direta.

O fato de o sistema de semeadura direta (SD) ter apresentado valores de $\mathrm{pH}$ mais baixos em profundidade no perfil do solo, comparativamente aos sistemas com preparo mecânico, não limitou o crescimento radicular avaliado por meio da densidade de raízes do milho (Tabela 4). A aplicação superficial do calcário, sem posterior incorporação, mantém na camada superficial concentrações adequadas de $\mathrm{Ca}$ e $\mathrm{Mg}$ que favorecem o desenvolvimento vegetativo. Deste modo, os menores valores de Ca (Tabela 9) e Mg (Tabela 10) em profundidade no sistema de semeadura direta são menores quando comparados principalmente com o preparo convencional (PC).

Tabela 9. Valores médios de cálcio (Ca), em diferentes profundidades, nos três sistemas de preparo do solo

\begin{tabular}{|c|c|c|c|c|c|c|}
\hline \multirow{2}{*}{ Sistemas de Preparo } & \multicolumn{6}{|c|}{ Profundidade $(\mathrm{m})$} \\
\hline & $0,0-0,1$ & $0,1-0,2$ & $0,2-0,3$ & $0,3-0,4$ & $0,4-0,5$ & $0,5-0,6$ \\
\hline & \multicolumn{6}{|c|}{ mmolc $\mathrm{dm}^{-3}$} \\
\hline SD & $26 a$ & $14 \mathrm{~b}$ & 7,0a & $6,0 \mathrm{a}$ & $7,0 \mathrm{a}$ & $8,0 \mathrm{a}$ \\
\hline $\mathrm{PE}$ & $23 a$ & $23 a b$ & $13 b$ & $7,0 \mathrm{a}$ & $7,0 \mathrm{a}$ & $10 \mathrm{a}$ \\
\hline PC & $23 a$ & $26 a$ & $21 c$ & $12 b$ & $9,0 \mathrm{a}$ & $9,0 \mathrm{a}$ \\
\hline $\mathrm{CV}(\%)$ & 17,6 & 20,3 & 19,2 & 26,6 & 21,7 & 24,8 \\
\hline
\end{tabular}

SD: Sistema de semeadura direta. PE: Preparo com arado escarificador. PC: Preparo com arado de discos. CV: coeficiente de variação. Números seguidos pela mesma letra não diferem entre si, na mesma profundidade, a $5 \%$ de probabilidade pelo teste de Duncan. 
Tabela 10. Valores médios de $\mathrm{pH}$ em $\mathrm{CaCl}_{2}$, em diferentes profundidades, nos três sistemas de preparo do solo

\begin{tabular}{lcccccc}
\hline \multirow{2}{*}{ Sistemas de Preparo } & \multicolumn{5}{c}{ Profundidade (m) } \\
\cline { 2 - 6 } & $0,0-0,1$ & $0,1-0,2$ & $0,2-0,3$ & $0,3-0,4$ & $0,4-0,5$ & $0,5-0,6$ \\
\hline SD & $4,8 \mathrm{a}$ & $4,6 \mathrm{a}$ & $4,2 \mathrm{c}$ & $4,3 \mathrm{~b}$ & $4,5 \mathrm{~b}$ & $4,8 \mathrm{a}$ \\
$\mathrm{PE}$ & $4,9 \mathrm{a}$ & $5,1 \mathrm{a}$ & $4,9 \mathrm{~b}$ & $4,6 \mathrm{~b}$ & $4,8 \mathrm{ab}$ & $5,0 \mathrm{a}$ \\
PC & $5,1 \mathrm{a}$ & $5,3 \mathrm{a}$ & $5,6 \mathrm{a}$ & $5,4 \mathrm{a}$ & $5,0 \mathrm{a}$ & $5,1 \mathrm{a}$ \\
\hline $\mathrm{CV}(\%)$ & 2,6 & 8,0 & 4,2 & 4,6 & 4,3 & 4,0 \\
\hline
\end{tabular}

SD: Sistema de semeadura direta. PE: Preparo com arado escarificador. PC: Preparo com arado de discos. CV: coeficiente de variação. Números seguidos pela mesma letra não diferem entre si, na mesma profundidade, a $5 \%$ de probabilidade pelo teste de Duncan.

Tabela 11. Valores médios de magnésio (Mg), em diferentes profundidades, nos três sistemas de preparo do solo

\begin{tabular}{|c|c|c|c|c|c|c|}
\hline \multirow{2}{*}{ Sistemas de Preparo } & \multicolumn{6}{|c|}{ Profundidade (m) } \\
\hline & $0,0-0,1$ & $0,1-0,2$ & $0,2-0,3$ & $0,3-0,4$ & $0,4-0,5$ & $0,5-0,6$ \\
\hline & \multicolumn{6}{|c|}{ mmolc dm $\mathrm{dm}^{-3}$} \\
\hline SD & $8,0 \mathrm{a}$ & $4,0 \mathrm{~b}$ & $2,0 \mathrm{~b}$ & $3,0 \mathrm{a}$ & $3,0 \mathrm{~b}$ & $4,0 \mathrm{a}$ \\
\hline PE & $8,0 \mathrm{a}$ & $6,0 \mathrm{~b}$ & $5,0 \mathrm{ab}$ & $3,0 \mathrm{a}$ & $3,0 \mathrm{~b}$ & $5,0 \mathrm{a}$ \\
\hline PC & $9,0 \mathrm{a}$ & $10 a$ & $7,0 \mathrm{a}$ & $6,0 a$ & $6,0 a$ & $5,0 \mathrm{a}$ \\
\hline CV $(\%)$ & 12,9 & 23,7 & 29,3 & 32,2 & 12,8 & 27,9 \\
\hline
\end{tabular}

SD: Sistema de semeadura direta. PE: Preparo com arado escarificador. PC: Preparo com arado de discos. CV: coeficiente de variação. Números seguidos pela mesma letra não diferem entre si, na mesma profundidade, a $5 \%$ de probabilidade pelo teste de Duncan.

Tabela 12. Valores médios de saturação por bases (V), em diferentes profundidades, nos três sistemas de preparo do solo

\begin{tabular}{|c|c|c|c|c|c|c|}
\hline \multirow{2}{*}{ Sistemas de Preparo } & \multicolumn{6}{|c|}{ Profundidade $(\mathrm{m})$} \\
\hline & $0,0-0,1$ & $0,1-0,2$ & $0,2-0,3$ & $0,3-0,4$ & $0,4-0,5$ & $0,5-0,6$ \\
\hline & & & 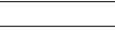 & 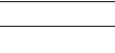 & -1 & 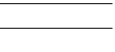 \\
\hline SD & $51 \mathrm{a}$ & $30 \mathrm{~b}$ & $17 \mathrm{c}$ & $18 b$ & $24 b$ & $28 \mathrm{a}$ \\
\hline PE & $51 \mathrm{a}$ & $53 \mathrm{ab}$ & $39 b$ & $25 b$ & $27 \mathrm{~b}$ & $37 \mathrm{a}$ \\
\hline PC & $55 a$ & $58 \mathrm{a}$ & $57 a$ & $44 a$ & $36 a$ & $36 a$ \\
\hline CV (\%) & 14,1 & 23,4 & 14,1 & 23,0 & 11,6 & 20,6 \\
\hline
\end{tabular}

SD: Sistema de semeadura direta. PE: Preparo com arado escarificador. PC: Preparo com arado de discos. CV: coeficiente de variação. Números seguidos pela mesma letra não diferem entre si, na mesma profundidade, a $5 \%$ de probabilidade pelo teste de Duncan.

Os valores de saturação por bases (V\%, Tabela 12), em função das alterações no $\mathrm{pH}$ do solo e, principalmente, dos teores de $\mathrm{Ca}$ e $\mathrm{Mg}$, seguiu a mesma tendência verificada para tais atributos, isto é, maiores valores nos tratamentos com preparo mecânico (PE e PC), quando consideradas camadas abaixo de 0,1 m. Esses resultados confirmam não haver diferenças em termos de fertilidade do solo na camada mais superficial (0,0-0,1 m) em função dos sistemas de preparo do solo. Em profundidade, porém, verificaram-se melhores condições de fertilidade nos tratamentos com preparo mecânico (PE e PC), não refletindo em maior concentração de raízes do milho.

A densidade de raízes de milho foi influenciada, provavelmente, pela camada de impedimento decorrente do uso do arado de discos, diagnosticada por meio dos resultados de densidade do solo, resistência do solo à penetração, infiltração e condutividade hidráulica (Tabelas 2, 3 e 5 respectivamente), em profundidade de cerca de 0,2 m.

\section{CONCLUSÕES}

1. No sistema de semeadura direta (SD) notamse os maiores valores de densidade do solo e de resistência à penetração na camada de 0,0-0,1 m de profundidade. Entre a camada de 0,05 m e de 0,20 m de profundidade, no preparo convencional (PC) houve aumento da resistência à penetração em torno de 3,5 vezes, caracterizando a presença do chamado "pe-degrade", uma vez que abaixo desta zona, com PC ocorre a metade da densidade de raízes presente em SD e PE. 
2. O sistema de semeadura direta (SD) permite maior taxa de infiltração e condutividade hidráulica do solo saturado em superfície e em profundidade, quando comparado com os sistemas de preparo mecânico (PE e PC), devido à maior continuidade dos poros no sistema SD.

3. Pelo sistema de semeadura direta, por sua vez, as melhores condições de fertilidade ocorre na camada de 0,0-0,1 m de profundidade devido ao acúmulo de nutrientes e corretivos nesta camada. A calagem realizada cinco anos antes da implantação do experimento proporcionou melhores condições de fertilidade do solo abaixo de $0,1 \mathrm{~m}$ de profundidade para o preparo convencional (PC), seguido do preparo escarificado (PE) e do sistema de semeadura direta (SD).

\section{REFERÊNCIAS}

ALMEIDA, J.A.; BERTOL, I.; LEITE, D.; AMARAL, A.J.;ZOLDAN JÚNIOR, W.A. Propriedades químicas de um Cambissolo Húmico sob preparo convencional e semeadura direta após seis anos de cultivo. Revista Brasileira de Ciência do Solo, v.29, p.437-445, 2005.

ASSIS, R.L.; LANÇAS, K.P. Avaliação dos atributos físicos de um Nitossolo Vermelho distroférrico sob sistema plantio direto, preparo convencional e mata nativa. Revista Brasileira de Ciência do Solo, v.29, p.437-445, 2005.

BERTOL, I.; BEUTLER, J.F.; LEITE, D.; BATISTELA, O. Propriedades físicas de um Cambissolo Húmico afetadas pelo tipo de manejo do solo. Scientia Agrícola, v.58, p.555-560, 2001.

BOHM, W. Methods of studing root systems. New York: Springer-Verlag, 1979. 189p.

CAMARGO, O.A., MONIZ, A.C; JORGE, J.A.; VALADARES, J.M.A.S. Métodos de análise química, mineralógica e física de solos do Instituto Agronômico de Campinas. Campinas: Instituto Agronômico, 1986. 94p. (Boletim Técnico n. 106)

CARVALHO, E.J.M.; FIGUEIREDO, M.S.; COSTA, L.M. Comportamento físico-hídrico de um podzólico vermelhoamarelo câmbico fase terraço sob diferentes sistemas de manejo. Pesquisa Agropecuária Brasileira, v. 34, p.257-265, 1999.

CIOTTA, M.N.; BAYER, C.; ERNANI, P.R.; FONTOURA, S.M.V.; ALBUQUERQUE, J.A.; WOBETO, C. Acidificação de um Latossolo sob semeadura direta. Revista Brasileira de Ciência do Solo, v.26, p.1055-1064, 2004.

CONTE, E.; ANGHINONI, I.; RHEINHEIMER, D.S. Frações de fósforo acumuladas em latossolo argiloso pela aplicação de fosfato no sistema semeadura direta. Revista Brasileira de Ciência do Solo, v.27, p.893-900, 2003.

COSTA, F.S.; ALBUQUERQUE, J.A. BAYER, C.; FONTOURA, S.M.V.; WOBETO, C. Propriedades físicas de um Latossolo Bruno afetadas pelos sistemas de semeadura direta e preparo convencional. Revista Brasileira de Ciência do Solo, v. 27, p.527-535, 2003.

EMBRAPA. Sistema brasileiro de classificação de solos. Brasília, Embrapa Produção de Informação, 1999. 412 p.

FALLEIRO, R.M.; SOUZA, C.M.; SILVA, C.S.W.; SEDIYAMA, C.S.; SILVA, A.A.; FAGUNDES, J.L. Influência dos sistemas de preparo nas propriedades químicas e físicas do solo. Revista Brasileira de Ciência do Solo, v.27, p.1097-1104, 2003.

FERRI, M.V.W.; VIDAL, R.A.; GOMES, J.; DICK, D.P.;SOUZA, R.F. Atividade do herbicida acetochlor em solo submetido à semeadura direta e ao preparo convencional. Pesquisa Agropecuária Brasileira, v.37, p.1697-1703, 2002.

FREITAS, P.L.; BLANCANEAUX, P.; GAVINELLI, E.; LARRÉ-LARROUY, M.C.; FELLER, C. Nível e natureza do estoque orgânico de latossolos sob diferentes sistemas de uso e manejo. Pesquisa Agropecuária Brasileira, v. 35, p.157-170, 2000.

GENRO JÚNIOR, S.A.; REINERT, D.J.; REICHERT, J.M. Variabilidade temporal da resistência do solo à penetração de um Latossolo argiloso sob semeadura direta com rotação de culturas. Revista Brasileira de Ciência do Solo, v.28, p.477484, 2004.

KLUTHCOUSKI, J.; FANCELLI, A.L.; DOURADO-NETO, D.; RIBEIRO, C.M.; FERRARO, L.A. Manejo do solo e o rendimento de soja, milho, feijão e arroz em semeadura direta. Scientia Agricola, v.57, 2000.

MARCOLAN, A.L.; ANGHINONI, I. Atributos físicos de um argissolo e rendimento de culturas de acordo com o revolvimento do solo em semeadura direta. Revista Brasileira de Ciência do Solo, v.30, 2006.

MARCOLAN, A.L.; ANGHINONI, I.; FRAGA, T.I.; LEITE, J.G.D.B. Recuperação de atributos físicos de um argissolo em função do seu revolvimento e do tempo de semeadura direta. Revista Brasileira de Ciência do Solo, Viçosa, v.31, p.571579, 2007.

RAIJ, B. van; QUAGGIO, J.A. Métodos de análise de solo para fins de fertilidade. Campinas: Instituto Agronômico, 1983. 31p. (Boletim técnico, 81)

REYNOLDS, W.D.; ELRICK, D.E. In situ measurement of field-satured hydraulic conductivity, sorptivity and the áparameters using the Guelph permeameter. Soil Science, v.140; p.292-302, 1985.

RHEINHEIMER, D.S.; ANGHINONI, I.; CONTE, E.; KAMINSKI, J.; GATIBONI, L.C. Dessorção de fósforo avaliada por extrações sucessivas em amostras de solo provenientes dos sistemas semeadura direta e convencional. Ciência Rural, v.33, p.1053-1059, 2003.

RHEINHEIMER, D.S.; ANGHONONI, I. Distribuição do fósforo orgânico em sistemas de manejo do solo. Pesquisa Agropecuária Brasileira, v.36, p.151-160, 2001. 
ROSOLEM, C.A.; FERNANDEZ, E.M.; ANDREOTTI, M.; CRUSCIOL, C.A.C. Crescimento radicular de plântulas de milho afetado pela resistência do solo à penetração. Pesquisa Agropecuária Brasileira, v.34, p.821-828, 1999.

SANTOS, H.P.; TOMM; G.O. Disponibilidade de nutrientes e teor de matéria orgânica em função de sistemas de cultivo e de manejo de solo. Ciência Rural, v.33, p.477-486, 2003.

SOUZA, Z.M.; ALVES, M.C. Movimento de água e resistência à penetração em um Latossolo Vermelho distrófico de cerrado, sob diferentes usos e manejos. Revista. Brasileira de Engenharia Agrícola e Ambiental, Campina Grande, v. 7, p.1823, 2003.

STONE, L.F.; MOREIRA, J.A.A. Efeitos de sistemas de preparo do solo no uso da água e na produtividade do feijoeiro. Pesquisa Agropecuária Brasileira, v.35, p.835-841, 2000.

TAYLOR, H.M.; BERNETT, E. Influence of soil strength on the root-growth habits of plants. Soil Science, v.98, p.174-180, 1964.

TOKURA, A.M.; FURTINI NETO, A.E.; CURO, N.; FAQUIN, V.; KURIHARA, C.H.; ALOVISI, A.A. Formas de fósforo em solo sob semeadura direta em razão da profundidade e tempo de cultivo. Pesquisa Agropecuária Brasileira, v.37, p.1467-1476, 2002.

VOLK, L.B.S.; COGO, N.P.; STRECK, E.V. Erosão hídrica influenciada por condições físicas de superfície e subsuperfície do solo resultantes do seu manejo, na ausência de cobertura vegetal. Revista Brasileira de Ciência do Solo, v.28, p.763$774,2004$.

WARRICK, A.W.; NIELSEN, D.R. Spatial variability of soil physical properties in the Field. In: Hillel, D. (ed.) Applications of Soil Physics. New York: Academic Press, 1980. Cap.2, p.319344 .

ZONTA, E.P.; MACHADO, A.A. Sistema de análise estatística para microcomputadores - SANEST. Pelotas: Universidade Federal de Pelotas, 1984. 